\title{
Performance of Roof Anchor Systems for Low-Income Housing in South Africa
}

\author{
Ruben van der Merwe ${ }^{1}$, Jeffrey Mahachi ${ }^{2}$ \\ University of Johannesburg, Johannesburg, South Africa \\ 1201122541@uj.ac.za; 2jmahachi@uj.ac.za
}

\begin{abstract}
The current methods for roof anchoring South African Low-Income Houses are described in the standard SANS 10400. The adequacy of these prescribed roof anchoring methods is questionable due to several recently reported failures caused by strong winds. This study investigates the performance of the prescribed roof anchoring methods through quantitative research and numerical methods, and focuses on LIH with light-weight roofs supported on single leaf masonry walls. The masonry walls comprise of solid bricks. The peak wind reaction forces that are expected to occur at the roof anchor systems were determined through a series of static analyses. Finite Element Analysis techniques were then performed to predict the capacity of the roof anchor system. The results of the research suggest that LIHs prescribed roof anchor systems constructed from solid bricks perform poorly under the expected South African strong wind climate. This study suggests further research is required to develop adequate roof anchoring methods for LIH with light-weight roofs, supported on solid brick walls and that the relevant codes be amended accordingly.
\end{abstract}

Keywords: Finite element analysis, low-income housing, masonry, roof anchors, wind damage

\section{Introduction}

South Africa has a huge housing backlog in excess of 2.4 million. To eradicate this backlog, the South African government provides a housing subsidy to households earning less than US\$234 per month [1]. The subsidies are used to construct houses commonly referred to as Low-Income Houses (LIH). Typically such houses have a foot-print of 36-60 square metres and the roofs are constructed with light-weight corrugated sheets $(0.5 \mathrm{~mm}$ thick $)$, and anchored to the walling system.

About five devastating wind events occur annually in South Africa, causing damage to structures and leaving thousands of people homeless, as cited in [2]. Blown-off roofs of LIH during strong winds have been recognised in a study by [3]. The roofs in such an event become flying objects with the potential of causing injury or death of humans and damage to surrounding buildings and infrastructure. Also, the roofs and support walls rely on each other for lateral support. Failure of the roof, therefore, also compromises the structural integrity of the support walls. Due to the likeliness of roofs blowing off during strong winds, many informal shelters and LIH use objects such as tires, bricks, or other heavy objects to assist in securing the roof. Fig. 1 [4] shows an example of such a case.

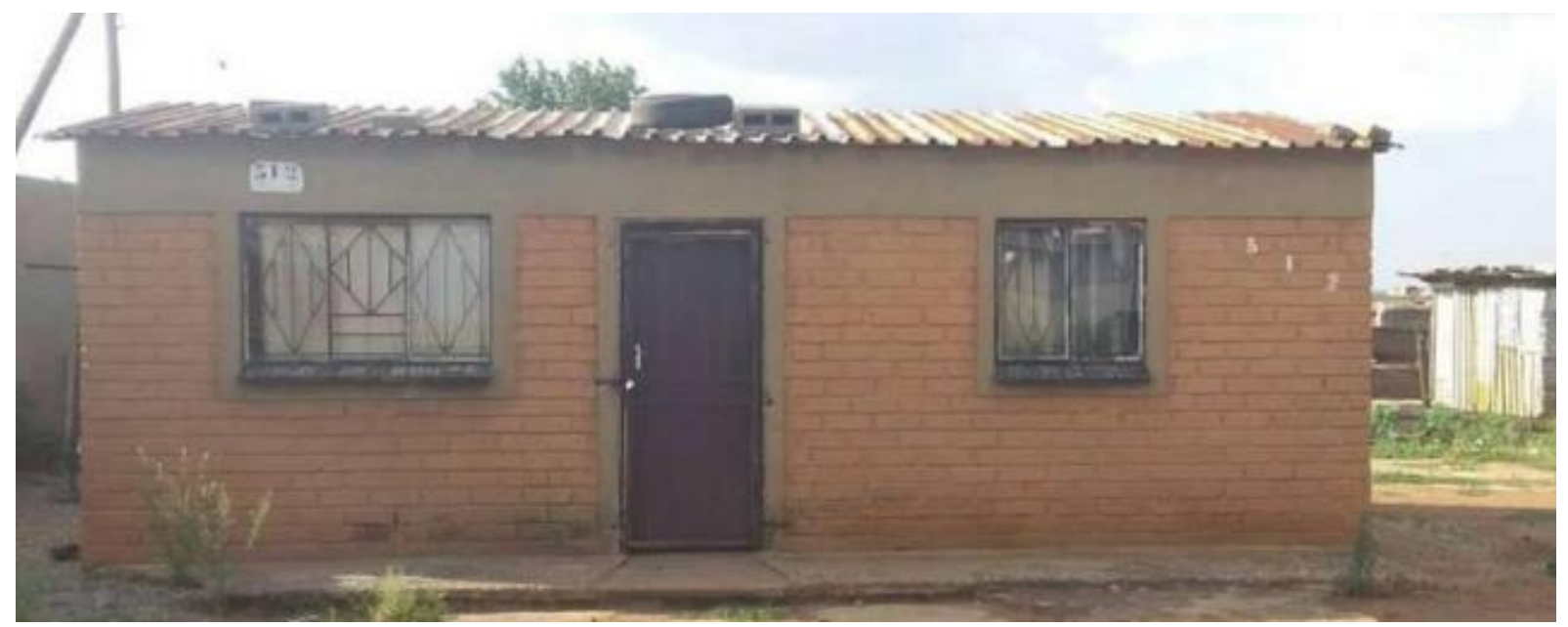

Fig. 1: Illustration of heavy objects used to secure roof against wind uplift. 
The current methods for anchoring roofs are prescribed in the South African standard SANS 10400-K [5]. A schematic illustration of the prescribed roof anchor methods for walls consisting of solid bricks is provided in Fig. 2.

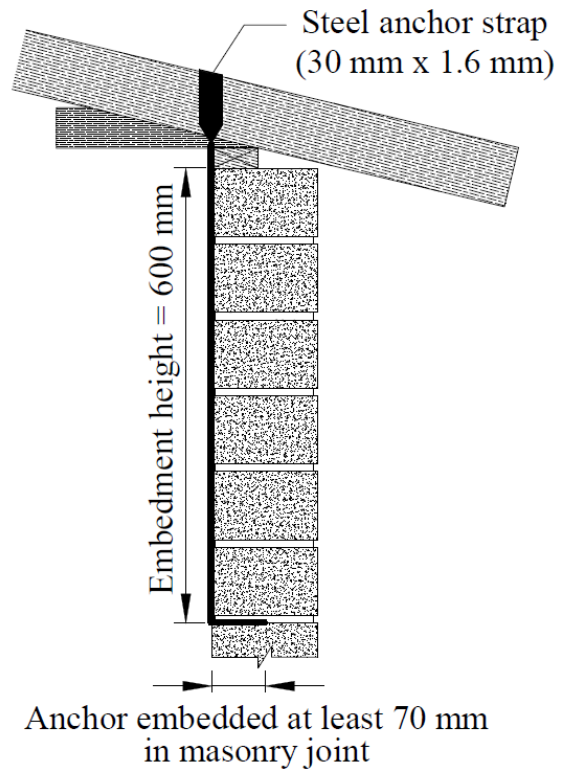

Fig. 2: Roof anchoring method for buildings with light roofs supported solid brick walls.

This research aims to determine the adequacy of the currently prescribed roof anchors for South African LIH under strong wind climate and provide recommendations for further research on the topic. The aim was achieved through the following objectives:

- to determine the expected wind uplift reaction forces at the roof anchor systems through static analyses;

- to predict the roof anchor system's performance against wind uplift through Finite Element Analyses (FEAs); and

- to determine the roof anchor system's adequacy by comparing the peak reaction loads expected at the roof anchors to the predicted resistance offered by the roof anchor systems.

\section{Methodology}

The study was conducted through quantitative research. The methodology of the research is divided into two main parts. The first part concerns the prediction of the peak wind reaction forces that are expected to occur at the roof anchor systems. The second part concerns the prediction of the roof anchor system's response.

\subsection{Determination of the wind uplift reaction forces at the roof anchor system}

The reaction forces at the roof anchor systems were determined through a basic static FEA conducted in Robot Structural Analysis software. Four distinct models, representing typical LIH with different roof configurations, were modelled. The models were designated as Model 1 to Model 4. The dimensions of the houses were kept constant, while the position of the external openings, representing the front door and windows, were altered. The geometry of the models was based on typical LIH in South Africa, as illustrated in Fig. 3. The roof anchor systems were resembled by defined support constraints. Resultant peak reaction forces were obtained, at the supports, for combined uplift wind loading and the self-weight of the roof structure and cladding. Truss or rafter spacings of $1.0 \mathrm{~m}, 1.2 \mathrm{~m}$, and $1.5 \mathrm{~m}$ were considered for each model. The roof slopes were taken as $12.5^{\circ}$ and $7^{\circ}$ for the duo-pitch and mono-pitch roofs, respectively. 

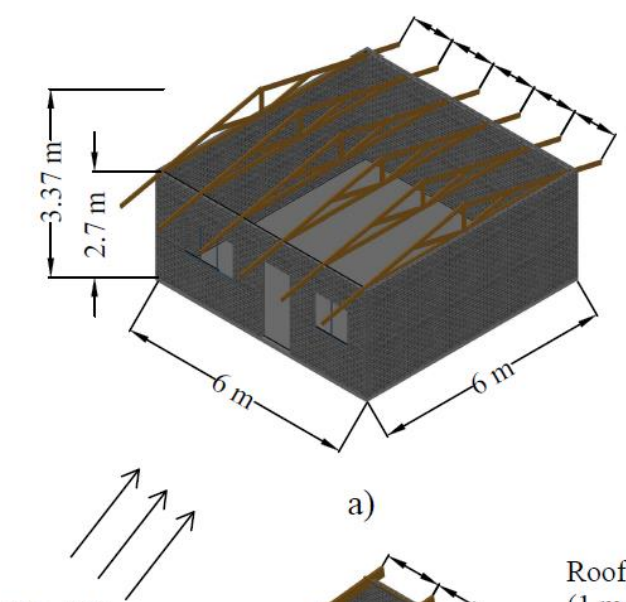

a)

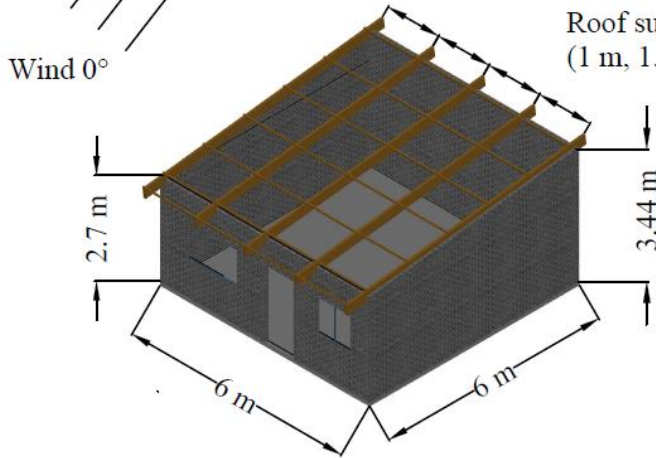

c)

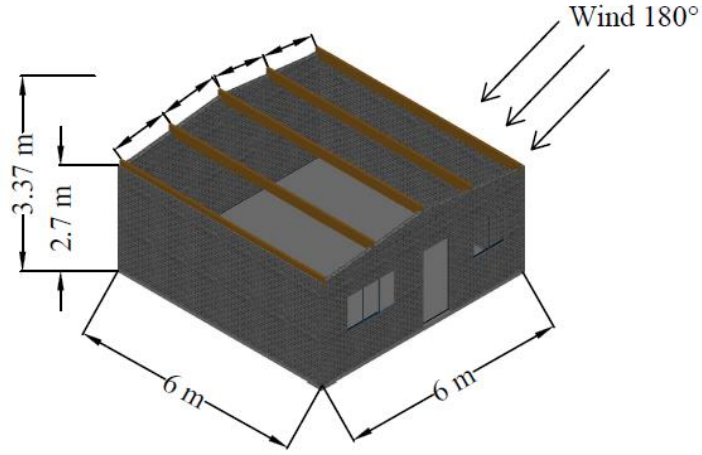

b)

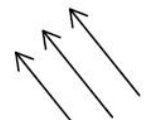

Wind $90^{\circ}$

Fig. 3: Wind loading directions and geometry of LIH: (a) Model 1, (b) Model 2, (c) Model 3, \& (d) Model 4.

The wind loading that acts on the roofs were calculated per the South African standard SANS 10160-3 [6]. The wind direction and wind pressure calculations were based on the following parameters:

- The peak wind pressures were calculated for the range of 1 in 50-year basic wind speed values provided on the wind map in SANS 10160-3 [6], i.e. $32 \mathrm{~m} / \mathrm{s}, 36 \mathrm{~m} / \mathrm{s}, 40 \mathrm{~m} / \mathrm{s}$, and $44 \mathrm{~m} / \mathrm{s}$. Besides, a basic wind speed of $25 \mathrm{~m} / \mathrm{s}$ was introduced to broaden the range of wind speeds of the investigation;

- The terrain category defined as "Category C" per SANS 10160-3 [6] were adopted to determine the peak wind pressures;

- Topography effects were ignored; and

- An accidental load case was considered by assuming a dominant wall in the case where the openings on the windward wall of the house are open through the failure of the door and windows.

\subsection{Predicting the response and resistance of the roof anchor system}

The resistance of the roof anchor system was predicted through FEA. The FEA was carried out in ABAQUS software. The roof anchor system was modelled to capture the capacity thereof due to the force applied through uplift wind pressure on the roof. The pull-out capacity of the roof anchor system was determined through load-displacement diagrams.

The modelling approach herein accounted for unit-mortar bond failure through defined surface contact interaction. Crushing and cracking of the masonry units and the mortar was accounted for by defined nonlinear behaviour of the Finite Elements (FE's) through the Concrete Damaged Plasticity (CDP) model. In this approach, a single part, referred to as a Representative Element (RE), was defined to represent a masonry unit as well as one bed joint below- and half the thickness of the head joints on either side of the masonry unit. The FE modelling approach is schematically presented in 
Fig. 4. Through this modelling approach, the amount of contact is significantly reduced without compromising the accuracy of the model.

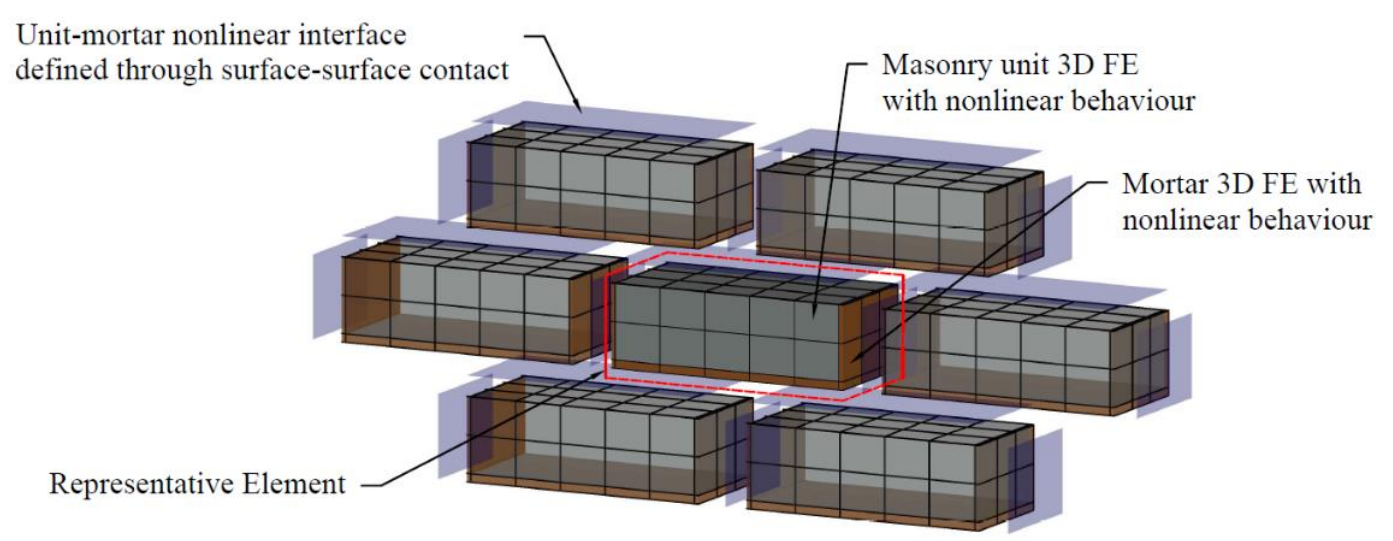

Fig. 4: An adopted approach for FE modelling of masonry components.

The roof anchor system concerns the roof anchoring methods per SANS 10400-K [5] for single leaf masonry walls consisting of solid bricks. The dimension of the wall assembly was chosen to accommodate a result comparison to potential future physical testing.

The assembly of the FEA model is illustrated in Fig. 5. A wall with dimensions of $1500 \mathrm{~mm}$ long, $700 \mathrm{~mm}$ high, and $140 \mathrm{~mm}$ thick were modelled. The parts were modelled using explicit 3D hexahedral shaped, eight-node, linear brick elements with reduced integration and hourglass control (type C3D8R elements).

The anchor was embedded between two brick courses at the prescribed depth of $600 \mathrm{~mm}$ from the top of the wall. The brick that is placed directly on top of the anchor is modified by subtracting a region to suit the anchor embedment and is referred to as the modified RE. The bonding of the anchor to the mortar was simulated through defined surfacesurface contact.

The entire bottom surface at the base of the wall was fully constraint against translation and rotation. A velocity constraint was applied to a reference point, defined at the top of the anchor, to simulate an upwards "pulling" force. The velocity constraint imposes displacement, producing a reaction force at the reference point. The reference point is used to capture the magnitude of the vertical (uplift) reaction force throughout the loading period.

Four groups of materials with distinctive mechanical- and interfacial bond properties for bricks and mortar were defined in the FEAs to consider the effect of the material properties on the performance of the roof anchor systems. The parameters of the first group, designated as "G1", were obtained from a study by [7] that covers an experimental investigation of the mechanical properties of masonry materials widely used to construct South African LIH and were therefore used as the benchmark material group for this study. The properties of the second group, designated as "G2", were obtained from [8], while the third and fourth group, designated as "G3" and "G4", respectively, where obtained from [9].

The mesh defined for the FEA model is presented in Fig. 6. The brick elements in the vicinity surrounding the anchor embedment are expected to experience high-stress gradients due to all of the loading being transferred from the anchor to the wall through the localised region. A refined mesh was introduced in the areas where high-stress gradients are expected. The mesh size was gradually increased towards the outer edges of the wall to reduce the computational time in areas with less interest. 


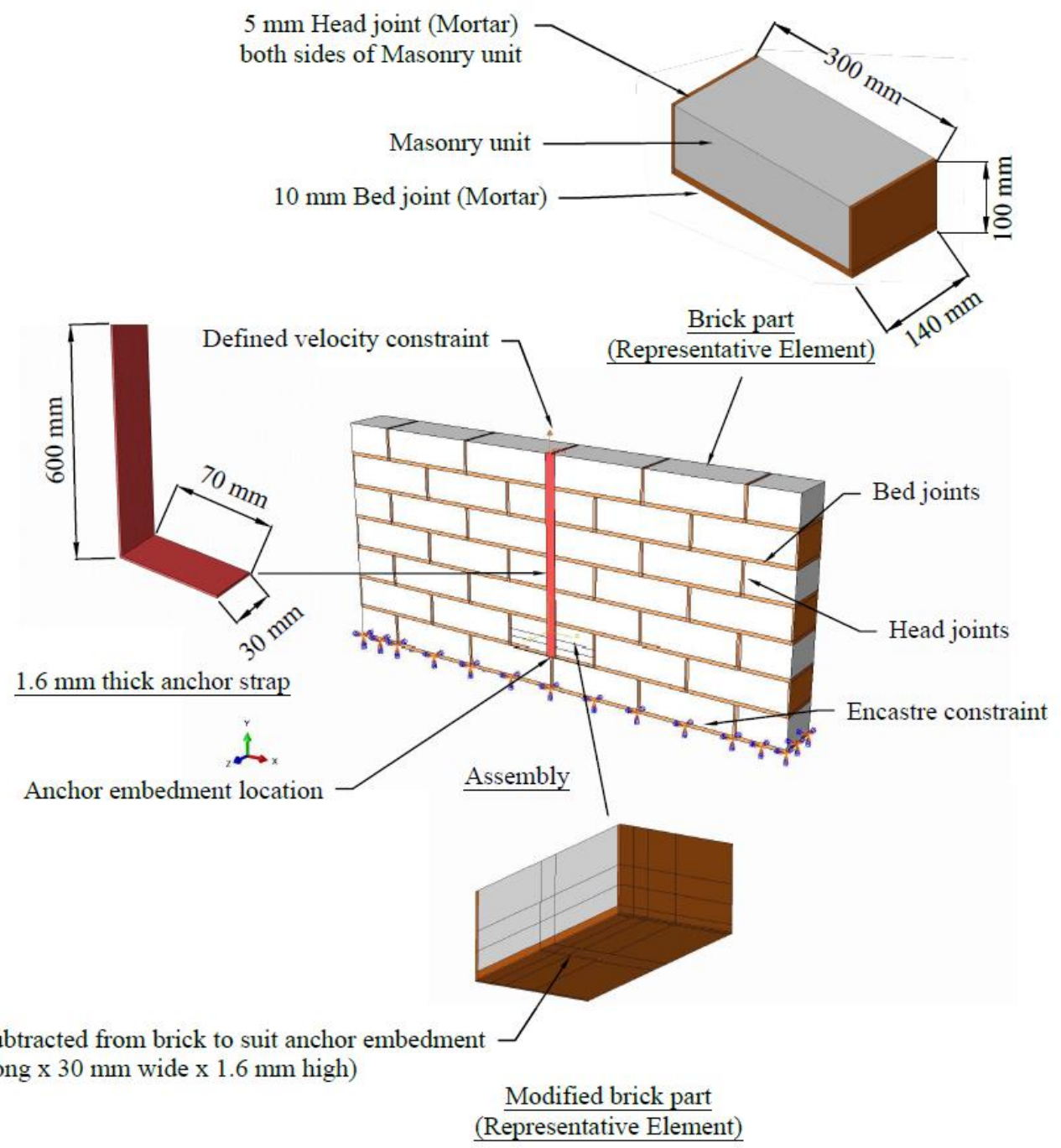

Fig. 5: Assembly of FEA model representing the roof anchor system.

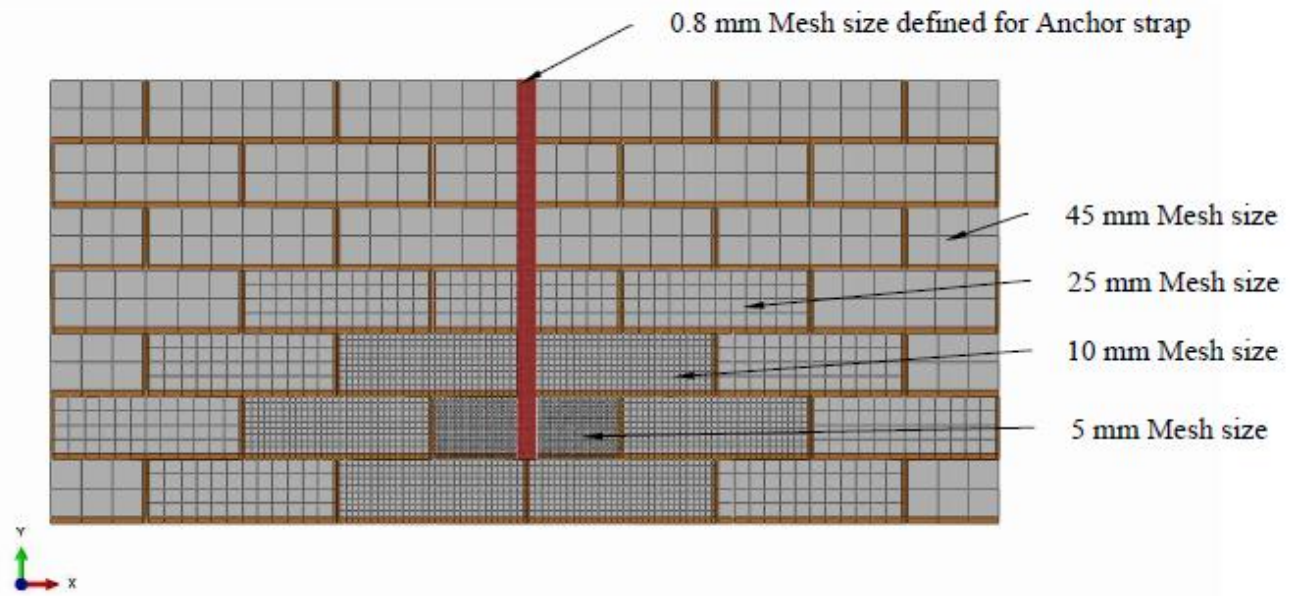

Fig. 6: Mesh defined for the FEA model. 


\section{Results and discussion}

The peak reaction forces obtained from the static analysis are presented in this chapter, followed by the predicted resistance of the roof anchor systems obtained from the FEAs. Next, a comparison is given between the reaction forces obtained and the predicted resistance of the roof anchor systems. The comparison presents the adequacy of the roof anchor systems.

\subsection{Reaction forces determined at the roof anchors}

Fig. 7 shows the maximum reaction forces obtained at the roof anchor systems for the basic wind speeds considered at $1.0 \mathrm{~m}, 1.2 \mathrm{~m}$, and $1.5 \mathrm{~m}$ roof support spacing. The maximum reaction forces were obtained from the range of LIH models that were considered in this study.

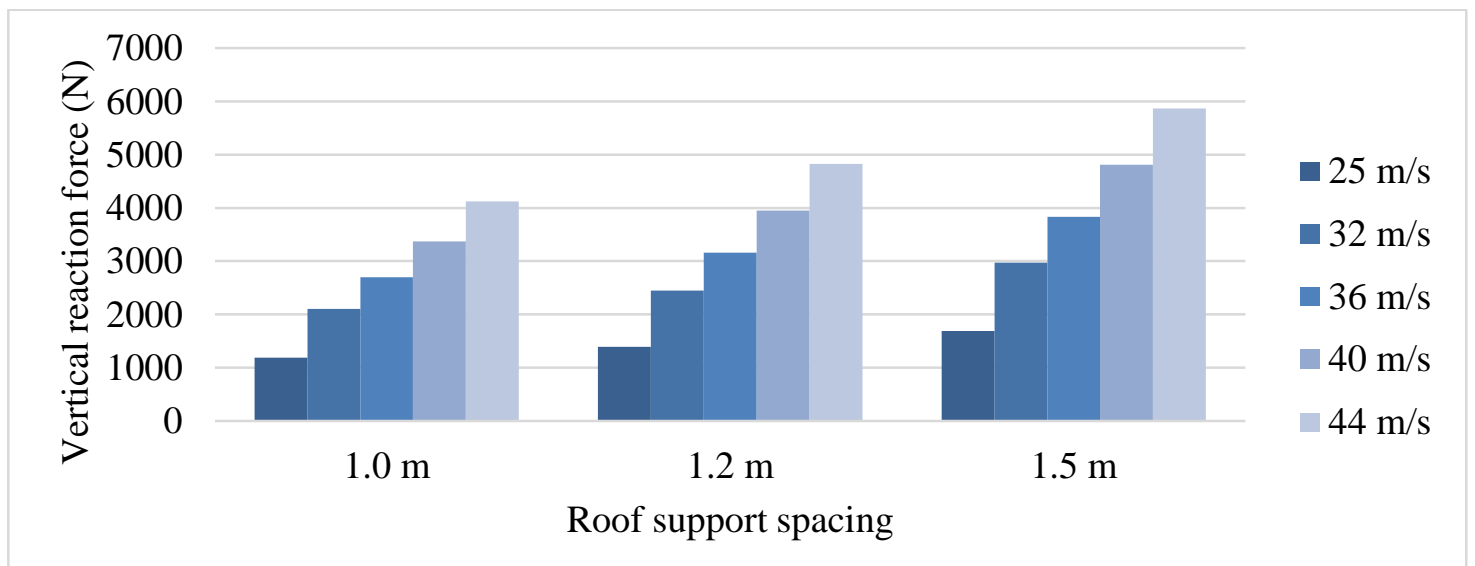

Fig. 7: Vertical reaction forces obtained at the roof anchors for the support spacings and basic wind speeds considered.

\subsection{Response of the roof anchor system}

The load-displacement curves presented in Fig. 8 show the applied force vs the free-end slip of the anchor strap for the material groups defined in this study. The ultimate capacity of the roof anchor system is represented by the maximum reaction force obtained throughout the loading history.

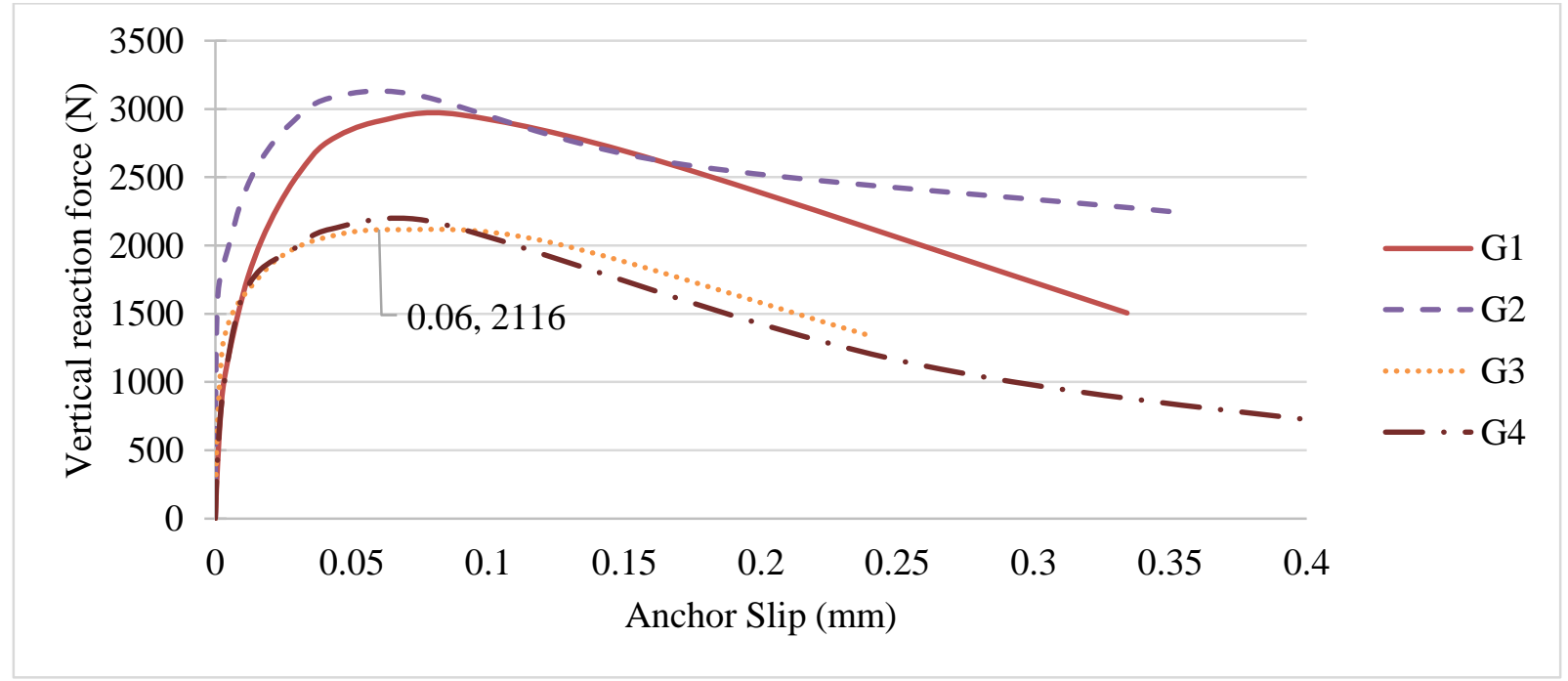

Fig. 8: Response of the roof anchor system for the material groups defined in this study. 
From Fig. 8, it is evident that a limiting resistance of about $2100 \mathrm{~N}$ was obtained and corresponds to material data groups "G2" and "G3". The ultimate failure of the roof anchor system was achieved through pull-out of the anchor strap as the bond strength was overcome. It was further noted that the resistance of the roof anchor system is dependent on the material properties of the masonry constituents and the brick-mortar bond strength.

\subsection{Predicted adequacy of the roof anchor system}

Fig. 9 presents the least resistance obtained from the FEA models, representing the capacity of roof anchor systems, as well as the reaction forces determined at the roof anchor systems against basic wind speed for different roof support spacings.

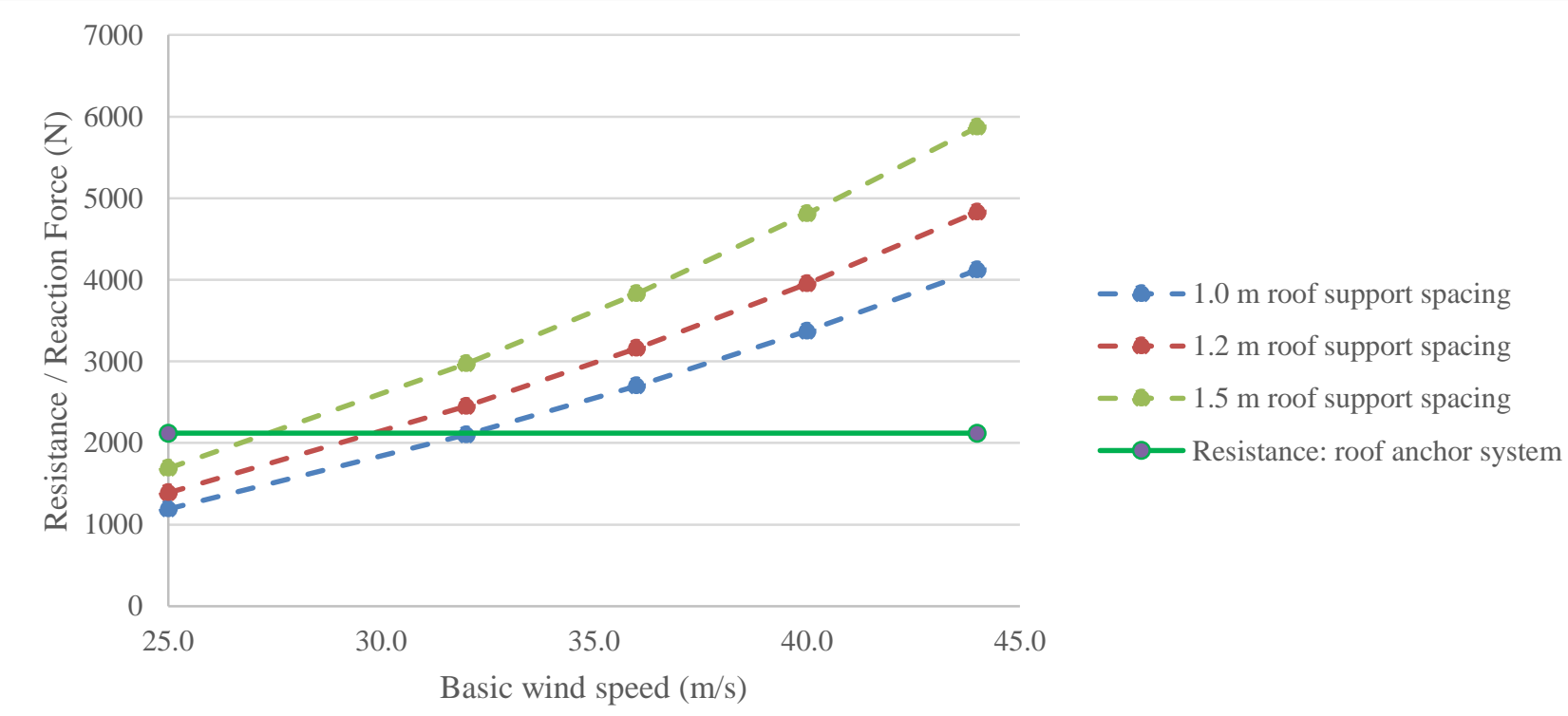

Fig. 9: Predicted resistance of the roof anchor systems compared to reaction forces expected at the roof anchor systems for various basic wind speeds at the roof support spacings considered.

The following observations were made from the Fig. 9:

- Failure of the roof anchor system for solid brick walls occurs at basic a wind speed of about $27 \mathrm{~m} / \mathrm{s}$ for LIH with roof support spacings of $1.5 \mathrm{~m}$.

- Failure of the roof anchor system for solid brick walls occurs at a basic wind speed of about $30 \mathrm{~m} / \mathrm{s}$ for LIH with roof support spacings of $1.2 \mathrm{~m}$.

- Failure of the roof anchor system for solid brick walls occurs at a basic wind speed of about $32 \mathrm{~m} / \mathrm{s}$ for LIH with roof support spacings of $1.0 \mathrm{~m}$.

- Overall, the roof anchor system for solid brick walls lacks sufficient resistance at the maximum basic wind speed that is expected to occur during the design life of South African LIH.

\section{Conclusion and recommendations}

This paper investigated the structural performance of the roof anchors systems for LIH with light roofs that are supported on single leaf solid brick masonry walls, as prescribed by SANS 10400-K [5]. The investigation was carried out through a quantitative research approach. FEA models were used to simulate the roof anchor system. The resistance predicted from the FEA models were compared to the expected reaction forces at the roof anchors that were determined from a series of static analyses. The reaction forces that are expected to occur at the roof anchor systems are based on the South African strong wind climate. SANS 10160-3 [6] was used to calculate the wind loading on the roofs. 
This study predicted that the prescribed anchoring method used in conjunction with single leaf solid brick walls are inadequate for $\mathrm{LIH}$ and failures are likely to occur during strong wind events. The results predicted that roof anchor failures might occur at basic wind speeds between $27 \mathrm{~m} / \mathrm{s}$ and $32 \mathrm{~m} / \mathrm{s}$ for LIH situated in areas with regular vegetation or buildings, depending on the roof support spacing. Failures might occur at lower basic wind speeds for LIH located in open areas with low vegetation. This study recommends further research for developing robust roof anchor systems for single leaf solid brick walls and that the local codes be amended accordingly.

\section{References}

[1] E. Msindo, "Housing Backlog: Protests and the demand for housing in South Africa, Public Service Accountability Monitor (PSAM)”, 2018. Accessed on July 10, 2020 [Online]. Available: http://psam.org.za/wp.

[2] A. M. Goliger, "Development of a wind damage and disaster risk model for South Africa," PhD dissertation, Dept. Civil Eng., Stellenbosch Univ., Stellenbosch, South Africa, 2002.

[3] O. Ogunfiditimi, "Assessment of structural quality of houses delivered through the People's Housing Process in South Africa," M.Tech. dissertation, Dept. Construction Management and Quantity Surveying, University of Johannesburg., JHB, South Africa, 2008.

[4] B. Mabuya and M. Scholes, "The three little houses: A comparative study of indoor and ambient temperatures in three low-cost housing types in Gauteng and Mpumalanga, South Africa," International Journal of Environmental Research and Public Health, vol. 17, no. 10, pp. 4, 2020.

[5] The application of the National Building Regulations, Part K: Walls, SANS 10400-K, 2011.

[6] Basis of structural design and actions for buildings and industrial structures, Part 3: Wind actions, SANS 10160-3, 2018.

[7] J. Fourie, "Characterisation and evaluation of the mechanical properties of alternative masonry units," M.Eng. thesis, Dept. Struct Eng., Stellenbosch Univ., Stellenbosch, South Africa, 2017.

[8] C. Santos, R. Alvarenga, J. Ribeiro, L. Castro, A Santos and G, Nalon, "Numerical and experimental evaluation of masonry prisms by finite element method," Revista IBRACON de Estruturas e Materiais, vol. 10, no. 2, pp. 477-508, April 2017.

[9] N. Agüera, M. Tornello, C. Frau, "Structural response of unreinforced masonry walls," Journal of Civil Engineering and Architecture, vol. 10, no. 2, pp. 219-231, Feb 2016. 